\title{
Impact of psychiatry clinical rotation on attitude of interns towards psychiatry
}

\author{
Dinesan N ${ }^{1}$, Rahul Bansal ${ }^{2}$, Arya Jith $^{3 *}$ \\ ${ }^{1}$ Professor and HOD, ${ }^{2}$ Junior Resident, ${ }^{3}$ Assistant Professor, Dept. of Psychiatry, Amrita Institute of Medical Sciences, Kochi, Kerala, India \\ *Corresponding Author: Arya Jith \\ Email: aryaji2008@gmail.com
}

\begin{abstract}
Background: Internship is a vital phase in medical student's training which can have a bearing on the attitude they develop towards various specialities. Limited studies have tried to assess the effect of clinical rotation on the attitude of interns towards Psychiatry. This study was planned to assess the same before and after a 2 week posting in Psychiatry.

Aim: To study the change in attitude of interns towards Psychiatry before and after clinical rotation in Psychiatry.

Materials and Methods: The study sample comprised of 100 interns in a tertiary care teaching hospital. Written informed consent was taken from the interns before the study. Appropriate ethical approval procedures were followed while taking consent from subjects and also in conducting the research. Attitude towards Psychiatry-30 was used to assess the attitude of interns towards Psychiatry before and after a 2 week Psychiatry rotation. Semi structured questionnaire was filled by interns regarding socio-demographic details and views about psychiatry. Non parametric tests were used to analyze the data obtained using SPSS software.

Results: This study showed favourable improvements in the ATP-30 score following exposure to the clinical rotation. There was a statistically significant change in mean difference of total global ATP 30 scores in males and females. Female gender found to have more positive attitude than males. The responses to 11 statements from ATP -30 scale showed statistically significant improvement after the posting.

Conclusion: The attitude of interns towards Psychiatry improved following a 2 week clinical rotation in Psychiatry. Further studies are needed to better understand the factors that may influence the attitude of interns.
\end{abstract}

Keywords: Attitude, Interns, Psychiatry, ATP-30.

\section{Introduction}

The overall weighted prevalence for any mental morbidity was $13.7 \%$ lifetime and $10.6 \%$ current mental morbidity in the National Mental Health Survey of India 2015-2016 Alarming finding was that the treatment gap for mental disorders ranged between $70 \%$ and $92 \%$ for different disorders. $^{2}$ The World Mental Health Atlas 2014 mentions the number of psychiatrists in India as 0.30 per 100,000 population, while the desirable number is around above 3 Psychiatrists per $100,000 .^{3}$ Considering this as the desirable number, 36,000 is the number of psychiatrists required to reach that goal. India is currently short of 27,000 doctors based on the current population of country. ${ }^{3}$ Data available showed the shortage of psychiatrist is varied and improvement is not uniform in the country. ${ }^{3}$ According to NMHS 2015-2016, Kerala had 1.2 psychiatrists per 100,000 population. ${ }^{1}$ The alarming shortage of number of psychiatrists can be estimated from the fact that all the other states fall short of 1-2 psychiatrist per 100,000 population which is the minimum requirement. ${ }^{1}$

Therefore, it is absolutely vital that more and more young doctors need to be trained as psychiatrists to bridge the gap. For that to happen effectively, a positive attitude towards psychiatry needs to be developed among medical students and young doctors besides increasing the opportunities available for training.

Internship is a vital phase during medical student's life and exposure to different specialities during this tenure is a good opportunity to understand student's inclination towards a specialty for future. Factors like personality, previous experience with a person with mental illness and influence of faculty members of psychiatry have been found to affect the attitude of medical students towards psychiatry. ${ }^{4}$ It is noteworthy that psychiatry patients have been stigmatised by society since ages and depicting the psychiatry ailments as violent, unpredictable and dangerous have contributed to stigma and this negative attitude. ${ }^{5}$ Such a negative attitude has been reported even in medical students which is a major point of concern. ${ }^{6}$ Such a negative attitude will, besides influencing students' future career choices, affect the care of psychiatry patients when dealt by other specialists at some point of time in their career. ${ }^{7-11}$ Therefore immediate attention towards destigmatization is the need of the hour. The medical curriculum in most Indian Universities provides a rotation of varying duration in psychiatry during internship. During the rotation they are expected to evaluate and manage the patients under the supervision of senior faculty. Building a positive attitude during this short duration may lead to more students opting for psychiatry as specialization. ${ }^{12}$ Understanding the impact of psychiatry clinical rotation on interns' attitude may give us valuable insight to further improve the current scenario. In our hospital, interns during the mandatory two week posting get adequate exposure in OPD and attend daily rounds of in-patients along with post graduates and consultants. Every intern posted in psychiatry gets an equal opportunity on the 24 hours duty to tag along the post graduates and consultants to see referrals from other departments. They get invaluable exposure to consultationliaison psychiatry and imbibe the knowledge to manage psychiatry patients with co-morbidities. They, during the 24 hours on call day, attend the Emergency calls along with post graduates and consultants and learn to manage psychiatry patients in crunch situations. 
Besides, they accompany the post graduates and consultants for the ECT sessions which help them resolve the myths about the shock therapy. Apart from such vast clinical exposure, interns also attend the seminars, case presentations and journal clubs held during the academic session daily along with post graduates and consultants. Daily attempts are made to add to their psychiatry knowledge so as to enable them to have a positive attitude towards psychiatry.

Existing literature is limited as few studies have been conducted in India to assess the attitude of medical students or interns towards psychiatry and results have been conflicting. Most of the previous studies have assessed the attitude in general without considering the impact of clinical rotation in psychiatry. A study has shown overall favourable attitude towards psychiatry patients when compared with medical patients. ${ }^{13}$ Few other studies have shown that such short duration was not sufficient to influence the attitude towards psychiatry significantly. Another study reported changes in certain aspects of attitude towards psychiatry patients. ${ }^{14}$ With this background, the current study was conducted to assess the impact of a 2 week clinical rotation on the attitude of interns towards psychiatry.

\section{Materials and Methods}

The present study is a cross sectional study done at the department of Psychiatry of $* * * * *$ Institute of Medical sciences over a period of 12 months. It is a tertiary care teaching hospital located in city $* * * * *$ of $* * * *$ state. The Institutional Ethical committee clearance was obtained before starting the data collection. We examined the effects of two week psychiatry posting of House surgeons in their attitude towards psychiatry. After explaining them the aim of the study and obtaining their informed consent, participants filled up the semi structured socio demographic profile. The questionnaire did not include any identifying information and participants were asked to drop the folded questionnaires into a designated box, whether completed, partially completed or not filled up at all, ensuring the students' anonymity. A standardized and structured questionnaire, Attitude Towards Psychiatry (ATP 30), was offered to all participants $(n=100)$ on the first and last day of clinical rotation in psychiatry. All 100 house surgeons returned the completely filled up questionnaires before and after the psychiatry posting.

ATP 30 is a 5-point Likert-type scale designed and validated in Canada by Burra et al. ${ }^{15}$ The scale consists of thirty positively and negatively phrased items that measure the strength of the respondent's attitude to various aspects of psychiatry. A score of 1 denotes a highly positive attitude, 5 denotes a highly negative attitude and 3 denotes a neutral response. The score of each positively phrased item is converted by subtracting it from 6 . The ATP score is the sum of total scores for positive and negative phrased items. The total global score ranges from 30 to 150 . A total global score of $<90$ suggests a negative attitude towards psychiatry, > 90 suggests a positive attitude towards psychiatry while a global score of 90 is considered to represent a neutral attitude. Each question of ATP-30 was analyzed independently and thematically with groups of questions together. The responses were recorded and the data so obtained was analyzed using SPSS version 21.For discussion purpose the questions in the ATP questionnaire have been divided under the following headings.

a) Attitude towards patient and illness b) Attitude towards knowledge and teaching c) Attitude towards psychiatry treatment and hospitals d) Attitude towards psychiatry and psychiatrists.

\section{Results}

100 house surgeons, females $(n=51)$ and males $(n=49)$, completed both the semi-structured questionnaire and ATP30.The pre-posting overall mean ATP-30 score was 90.17 $(\mathrm{SD}=9.62)$ and 22 students scored below the neutral point (90) indicating negative attitude towards psychiatry. The post-posting overall mean ATP-30 score was 120.35 (SD = 15.90) and only 9 students scored below neutral point. The difference in overall mean ATP-30 scores was statistically significant $(\mathrm{p}<0.05)$.The mean of Female and Male students pre-posting were 91.82 and 88.44 . The post posting mean of Female and Male students increased to 121.58 and 119.06 which was a statistically significant improvement in attitude towards psychiatry. Besides four positively framed and seven negatively framed ATP-30 statements (total = 11) showed statistically significant change after the two weeks posting in psychiatry rotation $(p<0.05)$.None of the statements showed change in negative direction.

Of the 100 interns who also completed semi-structured questionnaire, $70 \%$ of the interns think psychiatrists make lesser money than other specialists. $65 \%$ interns marked psychiatrists are not valued equally as other specialists in the society. Alarmingly, $81 \%$ interns think their family members would not allow them to pursue psychiatry as PG course even though $88 \%$ marked in favour of need of more psychiatrists in the country. 98\% interns think Mental Health in India needs to be focussed upon and 85\% marked implying that the scope of psychiatry in India is not bright. $76 \%$ interns think psychiatry patients are mismanaged by other specialties [Table 1].

Results of the ATP questionnaire are included in Table $2,3,4,5$

Table 1: Responses to the semi-structured questionnaire

\begin{tabular}{|c|l|c|c|}
\hline S. No & Questions & \multicolumn{2}{|c|}{ Response } \\
\cline { 3 - 4 } & & Yes & No \\
\hline 1 & $\begin{array}{l}\text { Do you know any one personally suffering from psychiatry } \\
\text { disorder? }\end{array}$ & 32 & 68 \\
\hline 2 & Have you ever suffered from psychiatry disorder? & 0 & 100 \\
\hline
\end{tabular}




\begin{tabular}{|c|l|c|c|}
\hline 3 & $\begin{array}{l}\text { Do you think psychiatrist make lesser money when } \\
\text { compared to other specialities? }\end{array}$ & 70 & 30 \\
\hline 4 & Do you feel ECT is gruesome? & 83 & 17 \\
\hline 5 & Do you think psychiatrist are valued equally in our society? & 35 & 65 \\
\hline 6 & Will you marry a psychiatrist? & 30 & 70 \\
\hline 7 & $\begin{array}{l}\text { Do you think your family members would allow you take } \\
\text { psychiatry as post-graduation course? }\end{array}$ & 19 & 81 \\
\hline 8 & Do you think India needs more psychiatrist? & 88 & 12 \\
\hline 9 & Do you think patients are reluctantto meet psychiatrist? & 85 & 15 \\
\hline 10 & $\begin{array}{l}\text { Do you think Mental Health needs to be more focussed } \\
\text { upon in India? }\end{array}$ & 98 & 2 \\
\hline 11 & Do you think scope of psychiatry in India is bright? & 15 & 85 \\
\hline 12 & $\begin{array}{l}\text { Do you think psychiatry patients are mismanaged by other } \\
\text { specialities? }\end{array}$ & 76 & 24 \\
\hline
\end{tabular}

Table 2: Responses to items measuring attitude toward psychiatric patients and illnesses

\begin{tabular}{|l|c|c|c|c|c|}
\hline \multicolumn{1}{|c|}{ Items } & $\begin{array}{c}\text { Pre posting } \\
\text { Agree }\end{array}$ & $\begin{array}{c}\text { Pre posting } \\
\text { disagree }\end{array}$ & $\begin{array}{c}\text { Post posting } \\
\text { Agree }\end{array}$ & $\begin{array}{c}\text { Post posting } \\
\text { disagree }\end{array}$ & $\begin{array}{c}\text { P } \\
\text { value }\end{array}$ \\
\hline Psychiatric illnesses need attention (12) & $18.07 \%$ & $81.93 \%$ & $26.05 \%$ & $73.95 \%$ & 0.06 \\
\hline Interesting to unravel the cause (18) & $38 \%$ & $62 \%$ & $39.5 \%$ & $60.5 \%$ & 0.11 \\
\hline Psychiatry patients are human (27) & $96 \%$ & $4 \%$ & $97 \%$ & $3 \%$ & 0.12 \\
\hline Psychiatric patients are interesting (29) & $15 \%$ & $85 \%$ & $15.7 \%$ & $84.3 \%$ & 0.14 \\
\hline
\end{tabular}

Table 3: Responses to items measuring attitude toward psychiatric knowledge and teaching

\begin{tabular}{|l|c|c|c|c|c|}
\hline Items & $\begin{array}{c}\text { Pre posting } \\
\text { Agree }\end{array}$ & $\begin{array}{c}\text { Pre posting } \\
\text { Disagree }\end{array}$ & $\begin{array}{c}\text { Post posting } \\
\text { Agree }\end{array}$ & $\begin{array}{c}\text { Post posting } \\
\text { Disagree }\end{array}$ & P value \\
\hline $\begin{array}{l}\text { Psychiatric teaching increases our } \\
\text { understanding of medical and surgical } \\
\text { patients. (9) }\end{array}$ & $37.7 \%$ & $62.3 \%$ & $39.2 \%$ & $60.8 \%$ & 0.16 \\
\hline $\begin{array}{l}\text { Students report that their psychiatry } \\
\text { undergraduate training has been } \\
\text { valuable (10) }\end{array}$ & $17 \%$ & $83 \%$ & $81.9 \%$ & $18.1 \%$ & 0.01 \\
\hline $\begin{array}{l}\text { Psychiatry has very little scientific } \\
\text { information to go on (13) }\end{array}$ & $84 \%$ & $16 \%$ & $26.2 \%$ & $73.8 \%$ & 0.01 \\
\hline $\begin{array}{l}\text { These days psychiatry is the most } \\
\text { important part of the curriculum in } \\
\text { medical schools (23) }\end{array}$ & $27.3 \%$ & $72.7 \%$ & $30.2 \%$ & $69.8 \%$ & 0.15 \\
\hline $\begin{array}{l}\text { Psychiatry is so unscientific that even } \\
\text { psychiatrists can't agree to what it's } \\
\text { basic applied sciences are.(24) }\end{array}$ & $69.5 \%$ & $30.5 \%$ & $28.2 \%$ & $71.8 \%$ & 0.01 \\
\hline $\begin{array}{l}\text { Most of the so-called facts in } \\
\text { psychiatry are just vague speculations. } \\
\text { (26) }\end{array}$ & $79.2 \%$ & $20.8 \%$ & $29.6 \%$ & $70.4 \%$ & 0.01 \\
\hline $\begin{array}{l}\text { Psychiatry is so amorphous that it } \\
\text { cannot really be taught effectively.(30) }\end{array}$ & $92 \%$ & $8 \%$ & $38.28 \%$ & $61.72 \%$ & 0.01 \\
\hline
\end{tabular}

Table 4: Responses of items measuring attitude toward psychiatric treatment and hospitals

\begin{tabular}{|l|c|c|c|c|c|}
\hline Items & $\begin{array}{c}\text { Pre posting } \\
\text { Agree }\end{array}$ & $\begin{array}{c}\text { Pre posting } \\
\text { Disagree }\end{array}$ & $\begin{array}{c}\text { Post posting } \\
\text { Agree }\end{array}$ & $\begin{array}{c}\text { Post posting } \\
\text { Disagree }\end{array}$ & P value \\
\hline $\begin{array}{l}\text { Psychiatric hospitals are little more } \\
\text { than prisons. (3) }\end{array}$ & $34 \%$ & $66 \%$ & $12 \%$ & $88 \%$ & 0.02 \\
\hline $\begin{array}{l}\text { It is quite easy for me to accept the } \\
\text { efficacy of psychotherapy (5) }\end{array}$ & $69.2 \%$ & $30.8 \%$ & $59.8 \%$ & $40.2 \%$ & 0.12 \\
\hline Psychotherapy basically is fraudulent & $66 \%$ & $34 \%$ & $6.1 \%$ & $93.9 \%$ & 0.01 \\
\hline
\end{tabular}




\begin{tabular}{|l|l|l|l|l|l|}
\hline$(8)$ & & & & & \\
\hline $\begin{array}{l}\text { With the form of therapy, most } \\
\text { psychiatric patients improve (14) }\end{array}$ & $13 \%$ & $87 \%$ & $73.6 \%$ & $26.4 \%$ & 0.01 \\
\hline $\begin{array}{l}\text { Psychiatric treatments causes patients } \\
\text { to worry too much about their } \\
\text { symptoms (16) }\end{array}$ & $79 \%$ & $21 \%$ & $13.9 \%$ & $86.1 \%$ & 0.02 \\
\hline $\begin{array}{l}\text { There is very little that psychiatrist can } \\
\text { do for their patients(19) }\end{array}$ & $59.5 \%$ & $40 . \%$ & $18.6 \%$ & $81.4 \%$ & 0.01 \\
\hline $\begin{array}{l}\text { Psychiatric hospitals have a specific } \\
\text { contribution to make to the treatment } \\
\text { of the mentally ill (20) }\end{array}$ & $37.2 \%$ & $62.8 \%$ & $78.7 \%$ & $31.3 \%$ & 0.01 \\
\hline $\begin{array}{l}\text { In the recent years psychiatric } \\
\text { treatment has become quite effective } \\
(25)\end{array}$ & $19 \%$ & $81 \%$ & $79.27 \%$ & $20.73 \%$ & 0.01 \\
\hline
\end{tabular}

Table 5: Responses to items measuring attitude toward psychiatrists and psychiatry

\begin{tabular}{|l|c|c|c|c|c|}
\hline Items & $\begin{array}{c}\text { Pre-posting } \\
\text { Agree }\end{array}$ & $\begin{array}{c}\text { Pre posting } \\
\text { Disagree }\end{array}$ & $\begin{array}{c}\text { Post posting } \\
\text { Agree }\end{array}$ & $\begin{array}{c}\text { Post posting } \\
\text { Disagree }\end{array}$ & P value \\
\hline $\begin{array}{l}\text { Psychiatry is unappealing because it } \\
\text { makes so little use of medical } \\
\text { training.(1) }\end{array}$ & $79.7 \%$ & $20.3 \%$ & $21.7 \%$ & $78.3 \%$ & 0.01 \\
\hline $\begin{array}{l}\text { Psychiatrists talk a lot but do very } \\
\text { little (2) }\end{array}$ & $87 \%$ & $13 \%$ & $17.2 \%$ & $82.8 \%$ & 0.01 \\
\hline $\begin{array}{l}\text { I would like to be a } \\
\text { psychiatrist (4) }\end{array}$ & $16 \%$ & $84 \%$ & $23 \%$ & $77 \%$ & 0.11 \\
\hline $\begin{array}{l}\text { On the whole, people taking up } \\
\text { psychiatric training are running away } \\
\text { from participation in real medicine. (6) }\end{array}$ & $67 \%$ & $33 \%$ & $49.4 \%$ & $50.6 \%$ & 0.01 \\
\hline $\begin{array}{l}\text { Psychiatrist seem to talk about nothing } \\
\text { but sex. (7) }\end{array}$ & $12 \%$ & $88 \%$ & $7 \%$ & $93 \%$ & 0.12 \\
\hline $\begin{array}{l}\text { Psychiatry is a respected branch of } \\
\text { medicine. (11) }\end{array}$ & $29 \%$ & $71 \%$ & $52 \%$ & $48 \%$ & 0.03 \\
\hline $\begin{array}{l}\text { Psychiatrist tend to be at least as stable } \\
\text { as the average doctor (15) }\end{array}$ & $37 \%$ & $63 \%$ & $73 \%$ & $27 \%$ & 0.01 \\
\hline $\begin{array}{l}\text { Psychiatrist get less satisfaction from } \\
\text { their work than other specialists (17) }\end{array}$ & $84 \%$ & $16 \%$ & $15.5 \%$ & $84.5 \%$ & 0.02 \\
\hline $\begin{array}{l}\text { If I were asked what I considered to be } \\
\text { the 3 most exciting medical } \\
\text { specialities, psychiatry would be } \\
\text { excluded table (21) }\end{array}$ & $94 \%$ & $6 \%$ & $22.3 \%$ & $77.7 \%$ & 0.01 \\
\hline $\begin{array}{l}\text { At times it is hard to think of } \\
\text { psychiatrist being equal to other } \\
\text { doctors.(22) }\end{array}$ & $47 \%$ & $53 \%$ & $58 \%$ & $42 \%$ & 0.12 \\
\hline $\begin{array}{l}\text { The practice of psychiatry allows the } \\
\text { development of really rewarding } \\
\text { relationships with people (28) }\end{array}$ & $37 \%$ & $63 \%$ & $78 \%$ & $22 \%$ & 0.01 \\
\hline
\end{tabular}

Attitude towards psychiatry questionnaire (ATP-30)

The following questionnaire is designed to ascertain the attitudes ot students toward the field of psychiatry. On the following pages you will find thirty (30) statements for which you are asked to indicate your own agreement or \& agreement on the IBM answer sheet.

There are live possible answer choices for each statement and you are asked to mark only one per statement. The answer categories are as follows:

A B C D E
A - Strongly agree
B - Agree
C - Neutral (no opinion)
D - Disagree
E - Strongly disagree

Thus, if you strongly disagree with a question. You will mark in the $\mathrm{E}$ space (as shown above). Please use an ordinary lead pencil and if you wish to change an answer. Please erase the first answer completely. Try to ensure that the statement number corresponds with the answer number 
you are marking Sometimes you may feel as though you have had the same item before on the questionnaire. This will not be the case so please do not try to remember how you checked similar items earlier on. Make each item a separate and independent judgement. Since this an attitudinal questionnaire it is important that your answers be "off the- top-of-the-head" rather than deliberately thought out.

Please answer all the questions

1. Psychiatry is unappealing because it makes so little use of medical training

2. Psychiatrist talk a lot but do very little.

3. Psychiatric hospitals are little more than prisons.

4. I would like to be a psychiatrist.

5. It is quite easy for me to accept the efficacy of psychotherapy.

6. On the whole, people taking up psychiatric training are running away from participation in real medicine.

7. Psychiatrists seem to talk about nothing but sex.

8. The practice of psychotherapy basically is fraudulent since there is no strong evidence that it is effective.

9. Psychiatric teaching increases our understanding of medical and surgical patients.

10. The majority of students report that their psychiatric undergraduate training has been valuable.

11. Psychiatry is a respected branch of medicine.

12. Psychiatric illness deserves at least as much attention as physical illness.

13. Psychiatry has very little scientific information to go on.

14. With the forms of therapy now at hand most psychiatric patients improve.

15. Psychiatrists tend to be at least as stable as the average doctor.

16. Psychiatric treatment causes patients to worry too much about their symptoms.

17. Psychiatrists get less satisfaction from their work than other specialists.

18. It is interesting to try to unravel the cause of a psychiatric illness.

19. There is very little that psychiatrists can do for their patients.

20. Psychiatric hospitals have a specific contribution to make to the treatment of the mentally ill.

21. If I were asked what I considered to be the three most exciting medical specialties, psychiatry would be excluded.

22. At times it is hard to think of psychiatrists as equal to other doctors.

23. These days psychiatry is the most important part of the curriculum in medical schools.

24. Psychiatry is so unscientific that even psychiatrists can't agree as to what its basic applied sciences are.

25 . In recent years psychiatric treatment has become quite effective.

26. Most of the so-called facts in psychiatry are really just vague speculations.

27. If we listen to them, psychiatric patients are just as human as other people
28. The practice of psychiatry allows the development of really rewarding relationships with people.

29. Psychiatric patients are often more interesting to work with than other patients

30. Psychiatry is so amorphous that it cannot really be taught effectively.

\section{Discussion}

This study showed a relative positive attitude towards psychiatry before two week psychiatry rotation which can be attributable to the way the subject is taught during the undergraduate days. In the fourth semester all students have compulsory two week clinical rotation in the department of psychiatry. Ten students will be posted at once, where students are taught how to communicate with the patient and how to elicit history and symptoms from the patients. During this period they are asked to work up cases and discuss it with the faculty. Besides this, twenty four hours of lecture time spread across six months is included in the sixth semester.

Among the hundred responses to the semi-structured questionnaire, $88 \%$ reported yes to "Do you think India needs more psychiatrist?" Surprisingly, only $23 \%$ reported to agree with Item number 4 of ATP-30 "I would like to be a psychiatrist" after the posting. This can be attributed to the fact that the interns think psychiatrists earn lesser money than other physicians, are respected lesser, do not have a bright future and their parents won't allow them to pursue Psychiatry as post graduation course as shown by their responses to the semi-structured questionnaire[Table 1]. This clearly implies that the interns understand the need for more Psychiatrists in the country but are themselves reluctant to pursue their career in Psychiatry. In a study conducted in Nigeria, the positive impact of clinical rotation on attitude towards psychiatry did not translate into their intention to specialize in psychiatry. ${ }^{4}$ In one study conducted in Spain which administered "Balon et al questionnaire", the percentage of students willing to choose psychiatry as their profession showed an increase from $4.2 \%$ before the psychiatry posting to $10.4 \%$ after the posting. ${ }^{8}$

\section{Attitude towards patient and illness [Table 2]}

We found that the interns showed positive attitude towards psychiatric patients and illnesses as $96 \%$ agreed that psychiatric patients are human just like other people.39.5\% agreed after posting that it is interesting to unravel the cause of psychiatry illnesses which was statistically significant $(p<0.05)$.This shows that stigma towards Psychiatry patients has reduced among interns but still the students are not willing enough to consider as their career choice. In an Indian study conducted among medical students and interns, Beliefs towards Mental Illness scale (BMI) and Attitudes to Mental Illness Questionnaire (AMIQ) were used. Females constituted $99 \%$ of the subjects and interns showed more positive attitude towards psychiatry patient and illness than medical students. ${ }^{13}$ 
Attitude towards knowledge and teaching [Table 3]

In this area, all interns agreed that psychiatry is the important part of the curriculum. $81.9 \%$ agreed after the posting that their psychiatry undergraduate training has been valuable (Item 10). After the posting, 73.8\% disagreed that "Psychiatry has very little scientific information to go on (Item 13). Most of the interns disagreed after the posting to "Psychiatry is so amorphous that it cannot really be taught effectively (Item 30)" showing that they had better understanding of the subject after the posting. Results of our study are encouraging in comparison to various studies conducted in Pakistan and Sri Lanka. ${ }^{16,17}$

\section{Attitude towards Psychiatric treatment and hospitals [Table 4]}

Further, students showed positive attitude towards psychiatric treatment and hospitals. Only $13 \%$ agreed to "With the form of therapy now at hand, most psychiatric patients improve (Item-14)" before posting which after the posting changed to $73.6 \%$ which was statistically significant $(p<0.05)$. After the two week rotation, $79.27 \%$ agreed that in recent years psychiatric treatment has become effective, almost all interns disagreed that psychotherapy is fraudulent and disagreed that psychiatric treatments cause patients to worry too much about their symptoms which were statistically significant. This significant improvement in their attitude can be attributed to the direct exposure of Interns to the management of the patients during the rounds and observing the improvement in them. These results are contradictory to the results showed by the study conducted in Bahrain and Nigeria which showed that there was no significant change in beliefs and that greater exposure to psychiatry changes the attitude of medical students. ${ }^{18,19}$

Attitude towards Psychiatry and psychiatrists. [Table 5] After the posting, interns had better understanding about how psychiatry treatment improves all the domains of patient's life. Existing literatures shows inconsistent findings. Yadav et al found that continuous education and training improved the attitude of medical students towards psychiatry patients. ${ }^{13}$ On the contrary, Rajagopalan $\mathrm{M}$ et al showed that 2 weeks exposure to Psychiatry as per the current curriculum was not sufficient to significantly influence students' attitude in a positive direction. ${ }^{19}$ In this study, results showed how vital is the Psychiatry clinical rotation in the curriculum as it improved their attitude significantly. Such a negative attitude before the posting can be subjected to ridiculous stereotypic comments and remarks by none other than medical practitioners belonging to other specialty branches. Al- Ansari et al reported the same issue in their study in 2002. It is not uncommon to find medical teachers suggesting poor public image of a psychiatrist. Remarks like psychiatrists do nothing more than prescribing sedatives and tranquilizers and their job is neither intellectually stimulating nor financially rewarding are commonly heard. It has also has been suggested that psychiatrists themselves are more susceptible to develop psychiatric disorders. ${ }^{20}$
To reduce this prevailing stigma globally and to make Psychiatry a preferable career option some remedies and possible interventions could be suggested. Duration of psychiatry posting should be increased rather than curbing it. Students will come to fully appreciate the work done by psychiatrists through their in depth exposure to the field. Students should be exposed to different subspecialties such as child psychiatry, addiction psychiatry, geriatric psychiatry and sleep and headache clinics. Emphasizing on the nature, prognosis and treatment of psychiatric illnesses having more chances of relapse such as substance dependence and schizophrenia can change their negative perception that psychiatrists cannot do much about their patients. Psychiatry should be introduced to the students in an innovative way. Demonstrating neurobiological basis of psychiatric illnesses with the help of modern neuro-imaging techniques in under graduation can create positive perception of Psychiatry. ${ }^{21}$

The limitations of this study include small sample size and inclusion of interns from one medical institution only. Therefore it is suggested that a study with larger sample having heterogeneous properties of subjects from different medical colleges across the country may be carried out or similar study may be conducted in the rest of the country to show the overall impression of the country. Besides, this improvement in attitude towards psychiatry might be a temporary change as the attitude was reassessed immediately after the commencement of the posting. To counter this limitation, studies assessing attitude towards psychiatry after a year or more after the psychiatry clinical rotation is completed can be conducted which will examine the long term effect of the clinical rotation.

\section{Conclusion}

The main aim of the study was to highlight the growing need for psychiatrist in our country; since the doctor patient ratio is very low. Our study showed that even though the stigma towards psychiatry and mentally ill patients was less in interns but still they were not willing to take it as a speciality. If the current National Medical commission takes steps to de stigmatise psychiatry and increase awareness among students, more students will consider taking Psychiatry as their profession.

\section{Source of Funding}

Nil.

\section{Conflict of Interest}

Nil.

\section{References}

1. Murthy RS. National mental health survey of India 2015-2016. Indian J Psychiatry. 2017;59(1):21.

2. Gururaj G, Girish N, Isaac MK. Mental, neurological and substance abuse disorders: Strategies towards a systems approach. Report submitted to the National Commission of Macroeconomics and Health. Ministry of Health and Family Welfare, Government of India, New Delhi. 2005. 
3. World Health Organization. Mental Health Atlas 2014. Geneva: WHO; 2015

4. Adebowale TO, Adelufosi AO, Ogunwale A, Abayomi O, Ojo TM. The impact of a psychiatry clinical rotation on the attitude of Nigerian medical students to psychiatry. Afr J Psychiatry. 2012;15(3).

5. Byrne P. Stigma of mental illness and ways of diminishing it. Adv Psychiatr Treat. 2000;6(1):65-72.

6. Lunn B. Recruitment into psychiatry: An International challenge. Aust New Zealand J Psychiatry. 2011;45(10):805-7.

7. Reddy JP, Tan SM, Azmi MT, Shaharom MH, Rosdinom R, Maniam T, et al. The effect of a clinical posting in psychiatry on the attitudes of medical students towards psychiatry and mental illness in a Malaysian medical school. Ann Acad Med Singapore. 2005;34 (8):505-10.

8. Bulbena A, Pailhez G, Coll J, Balon R. Changes in the attitudes towards psychiatry among Spanish medical students during training in psychiatry. Eur J Psychiatry. 2005;19(2):7987.

9. Malhi GS, Parker GB, Parker K, Carr VJ, Kirkby KC, Yellowlees P, Boyce P, Tonge B. Attitudes toward psychiatry among students entering medical school. Acta Psychiatrica Scand. 2003;107(6):424-9.

10. Ndetei DM, Khasakhala L, Ongecha-Owuor F, Kuria M, Mutiso V, Syanda J, et al. Attitudes toward psychiatry: a survey of medical students at the University of Nairobi, Kenya. Acad Psychiatry. 2008;32(2):154-9.

11. Niaz U, Hassan S, Hussain H. Attitudes toward psychiatry in pre-clinical and post-clinical clerkships in different medical colleges of Karachi. Pak J Med Sci. 2003;19(14):253-63.

12. Hemanthkumar BG, Keertish N, Sathyanarayana MT, Hyder S. Attitude of interns towards psychiatry before and after 2 weeks of clinical rotation. Indian J Soc Psychiatry. 2017;33(4):365.

13. Yadav T, Arya K, Kataria D, Balhara YP. Impact of psychiatric education and training on attitude of medical students towards mentally ill: A comparative analysis. Ind Psychiatry J. 2012;21(1):22.
14. Usha LV, Sireesha SR, Kumar CS. A cross sectional and comparative study of attitudes in undergraduate medical students towards psychiatric illness, cancer and diabetes mellitus. IOSR J Dent Med Sci. 2015;14:82.

15. Burra P, Kalin R, Leichner PW, Waldron JJ, Handforth JR, Jarrett FJ, et al. The ATP 30 - a scale for measuring medical students' attitudes to psychiatry. Med Educ. 1982;16(1):31-8.

16. Khan SA, Yousafzai AU, Mehir RK. Attitude of medical students towards psychiatry in NWFP. J Ayub Med Coll, Abbottabad: JAMC. 2008;20(3):44-6.

17. Rodrigo A, Wijesinghe C, Kuruppuarachchi KA. Changes in attitudes toward psychiatry with introduction of a new curriculum: experiences of a Sri Lankan medical school. SL $J$ Psychiatry. 2012;3(1):14-6.

18. Al-Ansari A. Attitude of Arabian Gulf University medical students towards psychiatry. Educ Health. 2002;15(2):180-8.

19. Olotu OS, Osahon PO. The effects of a clinical posting in psychiatry on the beliefs and attitudes of medical students towards the discipline. Niger J Psychiatry. 2001;5:305-13.

20. Rajagopalan M, Kuruvilla K. Medical students' attitudes towards psychiatry: Effect of a two week posting. Indian $J$ Psychiatry. 1994;36(4):177.

21. Rettenbacher MA, Burns T, Kemmler G, Fleischhacker WW. Schizophrenia: attitudes of patients and professional carers towards the illness and antipsychotic medication. Pharmacopsychiatry. 2004;37(03):103-9.

22. Jilowa CS, Meena PS, Jain M, Dhanda G, Sharma KK, Kumawat AK, et al. Attitude of undergraduate medical students toward psychiatry: A cross-sectional comparative study. Ind Psychiatry J. 2018;27(1):124.

How to cite this article: Dinesan N, Bansal R, Jith A Impact of psychiatry clinical rotation on attitude of interns towards psychiatry. Telangana $J$ Psychiatry. 2020;6(1):80-6. 